\title{
Homens brasileiros no mercado transnacional do sexo: apontamentos sobre trabalho sexual, migrações, discursos e imaginários*
}

\author{
Daniel Kerry dos Santos** \\ Mara Coelho de Souza Lago***
}

Resumo

Neste artigo apresentamos uma reflexão sobre o contexto sóciopolítico da inserção de homens brasileiros no mercado transnacional do sexo. Propomos uma breve contextualização acerca da questão das migrações de homens motivadas pelo mercado do sexo e um relato acerca de algumas dificuldades encontradas durante pesquisa de campo com esses sujeitos. Em seguida, analisamos as narrativas de alguns homens brasileiros trabalhadores do sexo residentes no Brasil. Demos destaque àquelas histórias que enunciavam o afeto do medo no mercado transnacional do sexo e o imaginário acerca dos fluxos migratórios. Consideramos que tais problematizações podem ampliar o debate sobre certas paisagens sociais sobre as quais se produzem algumas das experiências de homens trabalhadores do sexo.

Palavras-chave: Migração, Mercado Transnacional do Sexo, Prostituição Masculina, Sexualidade, Gênero.

* Recebido em 08 de setembro de 2017, aceito em 08 de junho de 2020.

** Doutor em Psicologia pela Universidade Federal de Santa Catarina (UFSC); professor do curso de Psicologia da Universidade do Sul de Santa Catarina (Unisul), Florianópolis, SC, Brasil. dakerry@gmail.com / https://orcid.org/0000$\underline{0002-5464-5010}$

*** Professora titular aposentada da Universidade Federal de Santa Catarina UFSC, Florianópolis, SC, Brasil. maralago7@gmail.com / https://orcid.org/0000$\underline{0001-5111-8699}$ 
Brazilian Men in Transnational Sex Trade: Notes on Sex Work, Migrations, Discourses and Imaginaries

\begin{abstract}
This paper reflects on the socio-political context of the insertion of Brazilian men in the transnational sex trade. Initially, the theme of male migration motivated by the sex trade is contextualized. Difficulties encountered in fieldwork with men in a migratory situation and working as sex workers are presented. We then analyze some narratives of Brazilian male sex workers in Brazil. We emphasize stories that enunciated the affect of fear in the transnational sex trade and imaginaries about migration flows. These problematizations can broaden the discussion about certain social landscapes in which male sex workers' experiences are produced.
\end{abstract}

Keywords: Migration, Transnational Sex Trade, Male

Prostitution; Sexuality, Gender. 


\section{Introdução}

Os processos migratórios e os fluxos de pessoas motivados pelo mercado (trans)nacional do sexo têm sido um tema amplamente discutido no campo dos estudos de gênero e de sexualidade e nos estudos feministas (Agustín, 2007; Barrero, 2005; Castañeda, 2014; Kempadoo e Doezema, 1998; Mayorga, 2011; Mitchell, 2010, 2011a, 2011b, 2019; Pelúcio, 2011; Piscitelli, 2013; Piscitelli, Assis e Olivar, 2011; Silva e Blanchette, 2005). Segundo Piscitelli, Assis e Olivar (2011) as pesquisas feministas sobre migração vêm demonstrando que as desigualdades de gênero são importantes vetores que marcam as circulações de pessoas. No entanto, salientam o/as autor/as, tais estudos têm dado pouca atenção ao sexo e à sexualidade no âmbito do mercado do sexo, de modo que podemos observar um silêncio em torno dessas temáticas. Além do mais, tradicionalmente quando se fala em migração para trabalhar no mercado do sexo, observa-se uma ênfase nas relações de gênero que envolvem homens (na posição de clientes) e mulheres (do lado da oferta).

Adriana Piscitelli (2013) alerta que o olhar fixo sobre essas posições também acaba silenciando reflexões sobre sujeitos que embaralham as fronteiras do gênero, como as travestis e mulheres transexuais, ou ainda sobre masculinidades e homens em situações migratórias, especialmente aquelas que acontecem motivadas pelo mercado do sexo. De fato, durante um levantamento bibliográfico sobre a produção acadêmica brasileira relativa ao trabalho sexual exercido por homens, encontramos poucas pesquisas que discutissem os deslocamentos e os trânsitos de garotos de programa, apesar de esses tipos de fluxos serem bastante frequentes, como observado na tese de doutorado de Santos (2016). Dentre as pesquisas sobre a temática em pauta, destacam-se as publicações de Gregory Mitchell (2010, 2011a, 2011b, 2019), pesquisador que nos últimos anos vem produzindo importantes problematizações acerca da indústria do sexo e do turismo sexual gay, do trabalho sexual exercido por homens 
brasileiros e dos intercâmbios culturais, afetivos e econômicos entre jovens garotos de programas e turistas gringos.

Diferentemente da recente atenção dada às marcas do gênero nos fluxos migratórios, sexo e sexualidade têm recebido pouca ênfase nas pesquisas sobre migração. Piscitelli, Assis e Olivar (2011) observam que tais estudos estão muito focados em grupos de pessoas supostamente heterossexuais que se engatam em fluxos migratórios motivados pelo "turismo sexual", que podem, ou não, envolver prostituição. Esse/as autor/as destacam, no entanto, que a maior parte dessas discussões acaba não focando nos afetos que entremeiam tais práticas: "[...] os afetos, sobretudo as emoções das pessoas de regiões pobres do mundo, têm recebido comparativamente escassa atenção, como se a importância adquirida pelos aspectos econômicos e sexuais apagasse as demais dimensões presentes nesses encontros" (Piscitelli, Assis e Olivar, 2011:08).

Nesse sentido, a temática das emoções, dos desejos e das subjetividades acaba sendo secundarizada. Os modos de subjetivação emergentes e a circulação dos afetos são, conforme aponta Mezzadra (2005), dimensões importantes que não podem ser negligenciadas nas análises das mobilidades humanas. Consideramos que tais perspectivas de análise, que consideram as emoções, os afetos $e$ a produção de imaginários $e$ de subjetividades, são igualmente fundamentais para problematizações acerca das dinâmicas dos mercados do sexo $e$ dos territórios geo-político-existenciais que se compõem nesses contextos. A esse respeito, lembramos que no clássico trabalho do antropólogo Néstor Perlongher (2008) sobre as territorialidades por onde circulavam os garotos de programa no centro da capital paulista durante a década de 1980, o autor já apresentava complexas análises sobre os imbricamentos entre afetos, subjetividades, poder e território no contexto da prostituição exercida por homens. Atualmente, como já mencionado, o pesquisador Gregory Mitchell tem desenvolvido pertinentes reflexões que articulam tais dimensões, especialmente nos 
contextos dos fluxos (trans)nacionais de homens trabalhadores do sexo (Mitchell, 2010, 2011a, 2011b, 2019).

Diante desse cenário de invisibilidades e silenciamentos, propomos algumas reflexões decorrentes de uma pesquisa de doutorado no campo da Psicologia Social Crítica. Nessa tese, traçamos cartografias que pudessem visibilizar o campo de forças $e$ de fluxos que atravessam e constituem as experiências de homens brasileiros trabalhadores do sexo. A pesquisa de campo se constituiu principalmente a partir da observação participante em saunas gays nas três capitais da região do sul do Brasil (Porto Alegre (RS), Florianópolis (SC), Curitiba (PR)) e na cidade de São Paulo (SP). Além das conversas informais com vários homens trabalhadores do sexo, também realizamos entrevistas em profundidade com 11 boys (como costumam se denominar tais sujeitos que atuam como trabalhadores do sexo) que atuavam naqueles espaços. Salientamos que apesar de as saunas se constituírem como nosso principal espaço de observação e de interlocução com esses sujeitos, elas não são os únicos locais onde os garotos atuam ou podem atuar. Nesse sentido, conforme defendido na tese de Santos (2016), consideramos que as saunas funcionam como pontos de territorialização do trabalho sexual, o que significa considerar que tais espaços e territorialidades estão necessariamente conectados a outras dinâmicas, circuitos $e$ territórios.

Neste artigo, inicialmente apresentamos uma reflexão sobre o contexto sócio-político da inserção de homens no mercado transnacional do sexo. Também relatamos algumas dificuldades encontradas durante pesquisa de campo com sujeitos em situações migratórias e que atuavam como trabalhadores do sexo. Após tais apontamentos, ensaiamos uma análise sobre algumas narrativas de homens brasileiros trabalhadores do sexo que foram nossos colaboradores durante a pesquisa. Demos destaque àquelas histórias que enunciavam o "afeto do medo" diante dos fluxos transnacionais e que puderam nos informar certa paisagem social sobre a qual se produzem algumas das experiências que se concretizam no mercado do sexo. 


\section{Homens no mercado transnacional do sexo: uma breve contextualização}

Temos observado que o mercado do sexo estimula várias modalidades de deslocamentos geográficos, constituindo diversos circuitos migratórios. Os homens trabalhadores do sexo também estão envolvidos nesses movimentos de desterritorialização, seja através de migrações pendulares, internas e/ou externas. As mobilidades empreendidas por tais sujeitos tanto podem representar movimentos migratórios a partir dos quais se busca estabelecer moradia fixa em uma nova localidade, como também podem compor aquilo que os boys costumam chamar de temporadas, ou seja, a permanência em uma região por um período de tempo que é determinado pela demanda local dos clientes. Nesse artigo, iremos focar nas dinâmicas do mercado transnacional do sexo $e$ seus agenciamentos macro $e$ micropolíticos, bem como nas narrativas de alguns boys brasileiros sobre suas experiências nesses contextos.

O processo de sair do Brasil para trabalhar como boy envolve a administração de diversos afetos, desde o prazer da "aventura", de conhecer outros países, de ter uma experiência de vida em lugares diferentes, de poder explorar o mundo e, ao mesmo tempo, ter a possibilidade de retorno financeiro; até o medo do desconhecido, de viver em outras culturas e entrar em contato com territorialidades e códigos diversos, de enfrentar problemas legais com a polícia e com políticas migratórias, e mesmo o fantasma do tráfico de pessoas que, como se verá adiante, também constitui o imaginário de homens trabalhadores do sexo, em situação migratória ou não.

O fluxo de garotos brasileiros para o exterior, especialmente para a Europa, é bastante significativo. Alguns estudos já indicaram que em países como Inglaterra e Espanha a maior parte dos homens trabalhadores do sexo migrantes é de sul-americanos, especialmente brasileiros (Fundación Triángulo, 2006; McGrathLoneet al., 2013). Também pudemos observar, seja por meio de sites de divulgação dos serviços de boys, ou através da 
interlocução com os colaboradores da pesquisa, a ampla circulação de boys do Brasil nesses dois países.

A partir dos relatos dos meus interlocutores ${ }^{1}$ no Brasil e de informações encontradas na internet, pude observar um fluxo migratório considerável de garotos de programa para a Espanha. O número expressivo de boys brasileiros atuando no território espanhol também foi verificado na pesquisa intitulada "Trabajadores Masculinos del sexo: aproximación a laprostitución masculina em Madrid', publicado em 2006 pela Fundación Triángulo. Segundo o relatório dessa pesquisa, a maioria dos homens trabalhadores do sexo que atuam em bares, pubs e/ou boates no Chueca, tradicional bairro gay de Madrid, é de origem latino-americana. Dentre os migrantes, seriam eles "em primeiro lugar do Brasil, seguido da Venezuela; em segundo lugar do Leste Europeu, particularmente da Bulgária, e por último de origem espanhola ou marroquina" (Fundación Triángulo, 2006:18-19). A predominância dos garotos brasileiros também se mantém nas saunas, porém nas casas de prostituição, os chamados "pisos", mantidas por proxenetas, a maioria dos boys seria "procedente da Venezuela, seguido do Brasil, Romênia, Espanha e Marrocos" (Fundación Triángulo, 2006:20-21).

Em uma matéria publicada em 2014 pelo site da BBC, muitos garotos de programa que vivem na capital inglesa lutam para "profissionalizar" suas atividades ${ }^{2}$. De acordo com a reportagem, alguns garotos conseguem obter um bom retorno financeiro e viver em localidades de alto custo. Ao realizar pesquisas em sites especializados em anunciar os serviços de garotos de programa na Inglaterra, observei que nesse país um garoto de programa chega a cobrar entre $£ 100$ a £300 a hora. Já o preço de um pernoite pode chegar a mil Libras ou mais, valores muito superiores, proporcionalmente ao Real, ao que se costuma

\footnotetext{
${ }^{1}$ Como nos itens a seguir o artigo tratará das experiências de pesquisa de campo do primeiro autor, o texto passará a ser redigido na primeira pessoa do singular.

${ }^{2}$ Fonte: http://www.bbc.co.uk/news/magazine-25588234; http://www.bbc.co.uk/portuguese/noticias/2014/01/140106 prostituicao masculin a londres mv.shtml
} 
cobrar no Brasil. Em minhas pesquisas de campo em contextos brasileiros, notei, a partir de observações em saunas, ruas e praças onde o trabalho sexual pode ser ofertado, que o preço médio da hora do serviço de um garoto de programa nas grandes capitais está em torno de $R \$ 100,00$, podendo variar para valores mais altos ou mais baixos, dependendo do território onde se está trabalhando e dos clientes com os quais se está negociando.

As informações da reportagem da BBC coadunam com o estudo de McGrath-Loneet al (2013) sobre a saúde sexual de homens trabalhadores do sexo na Inglaterra. Segundo os pesquisadores, aproximadamente um terço dos homens profissionais do sexo nesse país era de migrantes, principalmente originários do Brasil. Essa pesquisa apontou que das 50 diferentes nacionalidades dos homens participantes do estudo, $39 \%$ vinham da América do Sul, sendo que destes, $97 \%$ eram do Brasil. Já de acordo com informações contidas no documento Good practice guidance - Working with Migrant Sex Workers, produzido pela UK Network of Sex Work Projects (NSWP), a migração de homens trabalhadores do sexo aumentou no Reino Unido nos últimos anos, especialmente de sujeitos oriundos do Leste Europeu. Segundo consta nesse documento, os projetos sociais que atuam com a questão do trabalho sexual apontam que aproximadamente dois terços dos homens trabalhadores do sexo que vive em Londres são de migrantes (NSWP, 2008).

Os dados relativos à prostituição masculina no Reino Unido me eram de particular interesse, pois, durante o doutorado, realizei estágio doutoral na Inglaterra, onde morei por seis meses ${ }^{3}$. $\mathrm{O}$ tema da migração de homens brasileiros para trabalharem no mercado do sexo no Reino Unido não era o foco, nem o objeto da minha tese. No entanto, o fato de estar naquele país fez com que eu me interessasse por essa questão e buscasse ampliar meu campo de pesquisa. Passei a procurar mais informações sobre o

${ }^{3}$ Entre 2014 e 2015 fui contemplado com uma bolsa do Programa de Doutorado Sanduíche no Exterior (PDSE) da Capes para realizar um estágio doutoral na Inglaterra, na cidade de Manchester, em parceria com a instituição Discourse Unit, coordenada pela professora Erica Burman e pelo professor Ian Parker. 
contexto da prostituição (masculina e feminina) na Inglaterra, participei de alguns eventos locais sobre a temática e tentei estabelecer contatos com alguns garotos brasileiros que viviam por lá. Para a interlocução e o encontro presencial com os garotos brasileiros residentes no Reino Unido, porém, deparei-me com muitas resistências, o que acabou impossibilitando um contato maior com esses sujeitos, como discutirei mais detalhadamente a seguir.

Durante os seis meses em que morei na Inglaterra acessei frequentemente dois sites que considerei serem, naquele país, os principais veículos virtuais de divulgação dos serviços de homens trabalhadores do sexo (escorts ou rent boys, como são chamados): - SleepBoy (https://www.sleepyboy.com/), e o RentBoy (https://www.rentboy.com/). Através de sites como esses, os boys divulgam seus perfis e os clientes podem entrar em contato com aqueles profissionais de suas preferências, ver suas fotos, descrições dos atributos físicos, nacionalidade, etc. Na Inglaterra, o SleepBoy me pareceu o mais popular e o mais acessado.

Não posso deixar de mencionar um fato importante envolvendo o site RentBoy, outro website que usei como recurso de pesquisa quando morei na Inglaterra. Em agosto de 2015, quando já estava de volta ao Brasil, recebi a notícia de que a polícia de Nova Iorque, cidade estadunidense onde o escritório do site RentBoy era mantido, prendeu seis funcionários que trabalhavam na manutenção desse website e apreendeu diversos documentos que estavam guardados no local onde todos eles atuavam. Em decorrência dessa ação policial, o site foi retirado de veiculação sob a alegação das autoridades de que ele "promovia a prostituição" pelo país e entre as fronteiras nacionais, algo ilegal nos Estados Unidos da América. Segundo notícia publicada no site The New York Times ${ }^{4}$ em fevereiro de 2016, "as autoridades, que invadiram e fecharam o website, o chamaram de o maior serviço on-line de acompanhantes masculinos e o descreveram

\footnotetext{
${ }^{4}$ Fonte: http://www.nytimes.com/2016/02/18/nyregion/charges-dismissed-against6-ex-employees-of-rentboycom.html? $\mathrm{r}=2$
} 
como um bordel da Internet que lucrou milhóes de dólares promovendo a prostituição". As autoridades federais rejeitaram as acusações contra os/as funcionários/as do RentBoy e eles/as foram considerados/as inocentes, porém o episódio acabou se tornando mais um caso representativo no que tange às discussões sobre a regulamentação e descriminalização do trabalho sexual ao redor do mundo. A ação repressiva da polícia reergueu o debate sobre a problemática da criminalização do trabalho sexual e sobre as perspectivas abolicionistas que vigoram hegemonicamente em países como os EUA e o Brasil. O caso recebeu ampla cobertura da imprensa $e$ foi condenado por ativistas pelos direitos LGBT e de trabalhadores/as do sexo (Duggan, 2016). Movimentos LGBT de outros países também criticaram a investigação federal contra um website que vem funcionando publicamente há quase duas décadas e que é o site mais antigo e popular entre os homens trabalhadores do sexo. Em uma matéria publicada no site The Conversation $^{6}$, o trabalhador do sexo e ativista australiano Cameron Cox comentou:

\begin{abstract}
a batida no Rentboy.com suscita importantes questões sobre o trabalho sexual, incluindo sua visibilidade, a demanda do consumidor por esses serviços e a corrente marginalização daqueles/as que vendem e compram serviços sexuais. Se adultos racionais e em relações de consentimento escolhem se envolver em trocas sexuais comerciais, as autoridades deveriam estar desviando recursos da polícia para prevenir tais atividades? ${ }^{7}$ (Cox, 2015).
\end{abstract}

O caso RentBoy é emblemático no que diz respeito à produção de uma zona de marginalidade que recai sobre o trabalho sexual $e$ às constantes vigilâncias e punições que se dirigem às pessoas envolvidas nos mercados do sexo.

${ }^{5}$ Tradução livre do original em inglês.

${ }^{6}$ Fonte: https://theconversation.com/the-rise-and-fall-of-rentboy-com-46677

${ }^{7}$ Tradução livre do original em inglês. 
Trabalhadores/as do sexo ativistas no mundo todo vêm denunciando que essas racionalidades e práticas criminalizadoras não contribuem efetivamente com a proteção $e$ a garantida de direitos das pessoas que exercem diversos tipos de trabalho sexual. Ao contrário, tais ações repressivas não seriam capazes de extinguir a prostituição, mas apenas empurrariam as/os trabalhadoras/es do sexo para condições de trabalho mais precárias e para modos de vida mais vulneráveis (Agustín, 2007; Piscitelli, 2013). Essas constantes ameaças punitivistas criam um clima de medo e insegurança entre trabalhadores/as do sexo, sobretudo entre aqueles/as que se encontram em situação migratória.

De acordo com Piscitelli (2005), os debates contemporâneos relativos às regulações jurídicas sobre o mercado do sexo são marcados sobremaneira pela retórica do "tráfico de seres humanos com fins de exploração sexual". Segundo a pesquisadora (2005:11), as relações entre prostituição e migração "informam a promulgação de leis com diferentes graus de alcance". Piscitelli destaca ainda que há uma pressão internacional para reprimir o tráfico internacional de pessoas, o que acaba "interferindo" nas legislações "nacionais" (específicas de cada país) que regulam a prostituição. Esse debate se torna particularmente complexo, pois ao tentar proteger potenciais vítimas, tais leis "[...] incidem diretamente no desempenho de atividades nos mercados do sexo nacionais, na migração $e$, de maneira específica, nas vidas de migrantes indocumentados 'sem papéis"” (Piscitelli, 2005:11).

Penso que os contextos nos quais o trabalho sexual está rodeado de leis restritivas que não apenas regulam o mercado do sexo, mas também se articulam diretamente às políticas de migração, foram fatores que afetaram minhas tentativas de aproximação com os garotos de programa brasileiros que atuavam na Inglaterra. A ideia inicial quando fui para esse país era, além das atividades de estudos e intercâmbio acadêmico, fazer uma lista de contatos de garotos brasileiros que morassem no Reino Unido e que anunciassem seus trabalhos em sites como o 
SleepBoy e o RentBoy. A partir desses contatos, tentaria marcar um encontro em algum lugar escolhido pelo garoto para realizar entrevistas nas quais eu pediria para que me contassem sobre suas experiências como boys brasileiros migrantes trabalhando na Inglaterra. Como não conhecia os circuitos de prostituição naquele país, pensei que essa seria uma forma mais prática de contatar diretamente os brasileiros.

Por via desses sites, consegui vários contatos de boys brasileiros que atuavam em Londres, algo já esperado, haja vista os dados apresentados pela pesquisa de McGrath-Loneet al (2013). Com os contatos selecionados e anotados em meu diário de campo, viajei com certa frequência para Londres (cidade onde constatei haver a maior concentração de boys brasileiros), onde me hospedava por alguns dias, ligava para os garotos apresentando-me como pesquisador, e propunha-lhes uma conversa em algum espaço público perto de suas residências (oferecendo uma contrapartida financeira para o encontro). Durante esse tempo, liguei para mais de cinquenta garotos de programa brasileiros e, para minha "frustração", nenhum aceitou conversar comigo. Uns até concordaram em conceder uma entrevista, mas sempre algum "imprevisto" acontecia, o que fazia com que acabassem desistindo da proposta.

Durante as curtas conversas por telefone, alguns garotos diziam que não tinham "interesse em conversar", que não queriam "falar sobre isso", ou que estavam prestes a "viajar para outras localidades" e não poderiam "conversar no momento". Alguns chegaram a dizer que cobrariam um valor mais alto do que um programa para falar sobre suas vidas pessoais. O medo de se expor também me pareceu algo que dificultava o encontro com esses garotos. Um deles me disse que tinha viajado para Londres para começar um curso de graduação e que, caso descobrissem sua atividade como boy, não conseguiria dar continuidade aos seus projetos. Um dos garotos com quem pude conversar um pouco mais pelo telefone, disse-me que morar na Inglaterra era a "melhor coisa", que "amava a Europa" e que era "muito melhor estar lá, pois no Brasil havia muita pobreza". Disse também não 
querer voltar para o Brasil "de jeito nenhum", pois considerava que em seu país de origem "não há educação e tem muita corrupção e pobreza" e que se eu não tivesse que voltar por causa dos meus estudos, eu "certamente iria querer ficar por lá também".

Apesar dessas resistências que impossibilitaram minha aproximação com esses garotos, penso que algumas reflexões podem ser esboçadas diante da recusa do diálogo. A primeira questão que me atravessou para pensar sobre a rejeição em conversar comigo foi o contexto da imigração e o fato de exercerem uma atividade bastante marginalizada, sobretudo quando se é um trabalhador sexual imigrante. $\mathrm{O}$ fato de exercerem uma atividade "semi-criminosa" $e$, com isso, correrem o risco de serem deportados do país, me pareceu um bom motivo para tentarem se proteger contra possiveis problemas legais $e$ evitarem dar uma entrevista para um desconhecido. Segundo uma matéria publicada pela BBC $(2008)^{8}$ sobre as leis relativas à prostituição no Reino Unido, o ato de se prostituir naquele país por si só não é ilegal, mas há uma série de leis que criminalizam atividades que se relacionam com o sexo comercial. Ainda de acordo com o texto jornalístico, a manutenção de bordeis, a "vadiagem" (loitering), o ato de dirigir automóveis vagarosamente em regiões urbanas e solicitar o serviço sexual de transeuntes (trabalhadores/as do sexo ou não) (kerb-crawling), a divulgação de anúncios de serviços sexuais em cabines telefônicas, entre outras práticas similares, seriam atos contrários à lei no Reino Unido.

Em setembro de 2014 participei do evento "Sex Work and Human Rights Symposium: Lessons from Canada for the UK", organizado pela Durham University, na cidade de Durham, no norte da Inglaterra ${ }^{9}$. Durante minha participação nesse simpósio,

\footnotetext{
${ }^{8}$ Fonte: http://news.bbc.co.uk/2/hi/uk news/7736436.stm

$9 \mathrm{Na}$ ocasião pude acompanhar as discussões que ativistas e acadêmicos/as vinham promovendo naquele país. Entre os/as participantes, estavam mulheres profissionais do sexo $e$ ativistas dos importantes e históricos coletivos "EnglishCollectiveofProstitutes" e "Sex Workers Open University" (SWOU).
} 
conheci Kevin e Jane ${ }^{10}$, um homem e uma mulher que trabalhavam na instituição CLASH - Central London Action on Sexual Health. Durante algumas "conversas de corredor", pude falar com ambos sobre minha pesquisa de doutorado e perguntar sobre algumas dúvidas minhas relativas às condições de trabalho dos homens profissionais do sexo na Inglaterra. A CLASH está ligada ao sistema de saúde inglês, o National Health Service (NHS), e é uma instituição que oferece assistência em saúde sexual, especialmente para grupos vulnerabilzados. Por estarem inseridos em trabalhos comunitários de base e em contato direto com as populações locais, pensei que ambos poderiam me orientar em relação a algumas questões sobre a prostituição masculina em seu país. No entanto, eles não souberam me dar informações muito precisas sobre os homens trabalhadores do sexo na Inglaterra, o que pareceu reforçar minha percepção sobre a invisibilidade desses sujeitos naquele contexto.

Sobre as restrições legais no contexto britânico, Jane me explicou que se dois/duas ou mais profissionais do sexo atuam ao mesmo tempo no mesmo estabelecimento, isso caracterizaria a formação e manutenção de um bordel, algo proibido no Reino Unido. A matéria da BBC (2008) referida anteriormente também destaca essa questão: "se mais de uma pessoa (a lei é neutra em relação ao gênero) está disponível em um estabelecimento para o sexo pago, então isso seria um bordel. Entretanto, se uma mulher trabalha sozinha, ela não está mantendo um bordel ${ }^{11}$ ". Essa informação me pareceu muito importante para entender o porquê de eu não encontrar nenhuma sauna gay na Inglaterra na qual trabalhassem garotos de programa, como acontece recorrentemente no Brasil. A manutenção de saunas que abrigam o trabalho de boys seria uma atividade ilegal de acordo com as leis britânicas que regulam a prostituição, pois, nesse caso, tais estabelecimentos seriam enquadrados como bordeis ${ }^{12}$.

\footnotetext{
${ }^{10}$ Todos os nomes de interlocutores da pesquisa foram alterados.

11 Tradução livre do original em inglês.

12 A despeito da legislação que proíbe que garotos de programa atuem em saunas gays, Londres é uma cidade que comporta diversos estabelecimentos
} 
Em face às várias restrições impostas à prática do trabalho sexual, fica mais fácil entender os motivos pelos quais muitos trabalhadores do sexo acabem optando por oferecer seus serviços pela internet $e$ em espaços privados. As leis bastante restritivas quanto ao trabalho sexual também podem nos dar algumas pistas do porquê nenhum garoto brasileiro aceitou conversar comigo: o medo de ser penalizado por suas atividades me pareceu iminente naquele país onde o sexo comercial é bastante policiado.

Considero que os dados apresentados sobre a Espanha e a Inglaterra, bem como esse breve "relato etnográfico" produzido a partir de minha estadia no Reino Unido, funcionaram como uma sucinta contextualização (ainda que geograficamente localizada) sobre a questão dos homens inseridos no mercado transnacional do sexo. É interessante observar que em cada país há diferentes panoramas que regulam tanto a entrada de imigrantes quanto o exercício do trabalho sexual, o que nos coloca diante da necessidade de problematizarmos o trabalho sexual em contextos migratórios a partir de perspectivas interseccionais que considerem a articulação entre categorias como xenofobia, racismo, gênero, políticas migratórias, moral sexual, crimininalização/regulamentação do trabalho sexual, etc. Tais diferenças no trato com o tema em questão podem ser observadas, por exemplo, a partir das questões legais (como nos cenários proibicionistas ou mais ou menos restritivos quanto ao trabalho sexual); morais (como em países vistos como mais "conservadores" ou mais "liberais" em relação ao sexo); políticos (como nas políticas de austeridade em relação à entrada de imigrantes, especialmente no cenário atual de crises econômicas $e$ sociais na Europa); e culturais (como as diferenças de idioma, de costumes, etc.).

Essas diferenças podem se tornar critérios para a escolha de alguns destinos, mas não são os únicos determinantes que orientam esses fluxos. A promessa de um retorno financeiro

destinados a práticas sexuais entre homens, como clubes de sexo, saunas, boates e bares naturistas, entre outros. 
melhor que no Brasil também é um dos elementos importantes a ser considerado. É curioso observar, por exemplo, que apesar das várias restrições legais para o exercício da prostituição e para imigração na Inglaterra, o número de homens trabalhadores do sexo migrantes nesse país é bastante significativo. Provavelmente isso tenha relação direta com o fator econômico, uma vez que o pagamento naquele contexto é feito em Libras Esterlinas, uma das moedas mais valorizadas do mundo, com cotação superior ao Dólar e ao Euro.

Hulk, um dos interlocutores que conheci em uma sauna de Curitiba (PR) e que já tinha trabalhado como boy na Espanha, nos EUA e na Itália, pontuou sobre os benefícios econômicos de se trabalhar como boy no exterior: "Pagam melhor! Lá é uns 250 euros um programa. Vamos botar: 700 reais... É mais lucrativo! Por isso muita gente vai pra lá!'. Thor, um interlocutor que residia em Porto Alegre (RS)e que atua no mercado do sexo há vários anos e conhece muitas pessoas no ramo, também comentou sobre $\mathrm{o}$ fato de alguns conhecidos terem tido bons retornos financeiros com as experiências no exterior:

E tem muitos guris que se deram muito bem na vida. Conheço gente que tem casa na Suíça, tem casa em Paris, tem casa em um monte de lugar. Tenho amigos em vários lugares, em vários países do mundo. E aqui no país também. Um monte de lugar que for, São Paulo, Rio, Curitiba, eu conheço muita gente. Eu to na vida já vai fazer uns 15 ou 16 anos [...] Então eu conheço muita gente. (Thor, Porto Alegre)

Além dessas diferenças de contextos dos destinos, há também questões que dizem respeito aos desejos e projetos pessoais de cada sujeito: vontade de conhecer países e culturas diferentes, desejo de viajar, de explorar o mundo, de viver experiências em outros lugares onde o anonimato seria mais garantido, etc. É difícil precisar as motivações dessas migrações, mas o que pudemos observar é que a ideia de mudar de país para trabalhar como boyé algo muito recorrente no horizonte de vários 
trabalhadores do sexo brasileiros. No entanto, ainda que possamos perceber um campo de possibilidades para se engatar nos fluxos dos mercados transnacionais do sexo, muitos garotos relutam ou simplesmente decidem não se envolver nesses deslocamentos. No item a seguir me deterei na análise de algumas narrativas e imaginários que se constituem diante das (im)possibilidades de sair do país para trabalhar como boy.

\section{$\mathrm{O}$ afeto do medo no mercado transnacional do sexo e o imaginário ${ }^{13}$ acerca dos fluxos migratórios}

Se sair do país para trabalhar como boy aparentemente é algo lucrativo e uma ideia atraente, por que nem todos se engatam nesses fluxos? Por que mesmo diante de diversas possibilidades, propostas e caminhos para se inserir no mercado transnacional do sexo, muitos relutam em viajar? Além da questão da falta de necessidade ou interesse para se deslocar, também percebi outro elemento mais específico que atravessava as decisões de sair ou não do Brasil. Trata-se do afeto do medo (que se desdobrava em outros afetos como incertezas, inseguranças $e$ desconfianças) diante das possibilidades de viajar para o exterior a fim de trabalhar no mercado do sexo. Quando perguntei aos meus interlocutores se tinham interesse em trabalhar como boys em contextos internacionais, muitos expressaram medo e receio, afetos estes que se justificavam por conta de histórias de pessoas que foram e se "deram mal". Roger, de Porto Alegre (RS), por exemplo, contou-me que conheceu vários garotos que já tinham ido para outros países, como Portugal, Inglaterra e Holanda. Ele, porém, não planejava sair do Brasil, pois achava que não valeria a pena por considerar que em seu país estaria mais seguro: "Nunca

\footnotetext{
${ }^{13}$ Estamos usando o termo imaginário de acordo com a leitura de Ana María Fernández (2008) a respeito das teorizações de Castoriadis. Segundo Fernández, para Castoriadis o imaginário alude não à imagem, mas à capacidade imaginante, seja em sua forma instituída, que organiza as relações sociais numa aparência imutável e normativa; ou na sua forma instituinte, que estabelece linhas de fuga, produz novas significações coletivas e reinventa subjetividades.
} 
tive interesse [...] aqui é mais seguro! Vai pra fora e muito boy se fode lá fora. Aqui to perto de casa, posso ir embora fácil!".

Harry, de São Paulo (SP), relatou que já havia cogitado sair do país como acompanhante de um cliente estrangeiro, mas relutou e decidiu não ir, pois teve medo de que "algo de ruim" pudesse lhe acontecer. Entre as propostas para viajar com clientes desconhecidos, Harry optou apenas por aquelas que fossem para circular dentro do próprio país. Ainda assim, aceitava-as com certa prudência e cuidado, sempre atento às possíveis relações com clientes que pudessem se tornar "problemáticas":

[...] Um rapaz milionário, ele veio aqui e ele era maçônico. E nossa, ele se apaixonou por mim e eu tava casado. E ele queria porque queria me levar pra lá [...] Pra Nova Iorque. E eu falei: "não, não dá...". Isso faz um ano [...] Se eu não tivesse com a minha mulher, eu tinha ido. Mas ai também vem aquela questão do medo, né? Você não conhece a pessoa, ela tem dinheiro pra caralho e pode fazer o que quiser com você. Mas recebi essa proposta dele e foi muito tentadora. Recebi uma proposta até de um rapaz que tava aqui ontem. Ele mora no Texas, nos Estados Unidos. Eu não quis ir. (Harry, São Paulo)

Semelhantemente a Harry, Frank, de Porto Alegre (RS), também relatou nunca ter tido experiências no exterior como boy, apesar de já ter recebido convites para viajar para outros países. Tinha medo das diferenças culturais que poderia encontrar em contextos internacionais, por isso restringia suas temporadas dentro do próprio país, onde se sentia seguro e não considerava haver tanto perigo como supunha haver fora do Brasil.

É... então assim, no Brasil é tudo de bom... Tenho receio de sair, em questão de... cada país tem sua cultura. E isso ai é complicado. Nem todos os países têm a mesma cultura. De tratar o ser humano, o acompanhante, o garoto, né? Ai às vezes eu fico com receio disso. (Frank, Porto Alegre) 
Thor, apesar de já ter saído do país para trabalhar como boy, relatou algumas situações que fizeram com que ficasse mais atento $e$ cuidadoso em relação às redes pelas quais circulava e nas quais se envolvia no exterior. A primeira vez que foi para a Europa, a convite de um cliente espanhol, disse que ficou bastante relutante e que teve medo de que algo de ruim poderia the acontecer:

[...] daí começaram as propostas de ir pra fora. Uma vez um cliente que eu conhecia já, era de Barcelona, chegou e falou: "não quer ficar uma semana comigo, em Barcelona, na minha casa? Te levo numa sauna pra você conhecer, até deixo você trabalhar, se você quiser...". Ai ta, eu tava meio assustado, mas ele tinha passaporte e tudo. Mas eu fui meio assustado, sabe? "Ah, e se me matam lá, vão falar o que? Já era..."Ai eu dei um tiro no escuro, mas graças a deus deu tudo certo. (Thor, Porto Alegre)

Na experiência de Thor, o risco assumido ao sair do Brasil, o "tiro no escuro", não resultou em nenhum tipo problema. A decisão de viajar com o cliente, no entanto, não foi tomada com muita segurança e o medo de sofrer algum tipo de violência inclusive de ser morto, foi algo que atravessou sua decisão. Após sua primeira temporada na Europa, Thor passou a entender melhor o funcionamento do mercado do sexo naquele contexto $e$ a encontrar formas de como se inserir naquelas redes de prostituição de maneira relativamente mais autônoma. Contou-me que durante essas temporadas nunca teve problemas ou experiências traumáticas.

A partir das conversas que tive com Frank e Thor, notei que esse receio de sair do país se relacionava diretamente com as histórias que tomaram conhecimento acerca de garotos que foram para a Europa e que, segundo seus relatos, tiveram problemas com as redes com as quais se envolveram naquele contexto. Dentre algumas das problemáticas relatadas, estavam $\mathrm{O}$ aprisionamento de passaporte e acúmulo de dívidas com figuras que exerciam a função de "cafetões". Durante uma de suas 
temporadas na Espanha, Thor conheceu um garoto brasileiro em Madrid que estava em situação de exploração e que lhe pediu ajuda para tentar fugir. No relato de Thor, percebe-se o medo das redes de exploração de trabalhadores do sexo migrantes no contexto espanhol:

[...] eu tive amigos que já tiveram muitos problemas. Tem uns que eu nunca mais nem ouvi falar. Não voltaram mais. Aí têm facções de prostituição, têm muitas facções de prostituição. Te levam e tu tem que ficar pagando, né, como eu conheci uns guris lá. Eles te dão passagem, hospedagem. Tudo pago. Ai chega lá e eles querem te cobrar 4, 5, 6 vezes mais do que eles combinaram contigo. Então tu fica trabalhando e tu tem que ficar 4, 5 meses lá. Tem três meses que tu pode ficar, ai eles te deixam três meses clandestino pagando, ai, resumindo, tu volta com nada [...] Mas de lá eu conheci muitos amigos [...] Tinha um amigo meu numa sauna lá, que bah, tava quase chorando, ta ligado? Porque: "meu não posso sair daqui porque já tão me esperando lá fora!". Tem amigo meu que pediu ajuda, pra ligar pra familiares. Já liguei, cheguei a ligar lá de fora. Lá em Madrid liguei pro familiar do amigo meu e falei a verdade pra família dele: "seguinte, ele veio pra se prostituir, mas não tá conseguindo pagar os caras. Os caras tão cobrando mais do que devia". Aí eu não podia fazer nada, isso era o que eu podia fazer, né? No dia seguinte eu falei: "Dei o recado pra tua mãe". E ele: "ah, mas tu falou tudo?". Eu: "Falei, né? Falei tudo, tinha que falar, né? Falei a verdade...".Mas aí também não sei mais o que aconteceu com ele. Depois disso, eu nunca mais vi ele. Depois disso eu fui pra Barcelona, não voltei mais pra Madrid e não vi mais ele. Cara tem muitas coisas ruins que acontecem. (Thor, Porto Alegre)

Frank, que nunca teve experiências fora Brasil e nem tinha interesse em viajar, também relatou uma história de um conhecido muito parecida: 
[...]colegas já foram e eu nunca mais vi [...] Eu tinha um amigo, que quando eu comecei a ir pra São Paulo, eu levei ele junto pra apresentar pra outro cliente. Aí esse outro cliente era amigo de um cliente meu, que nunca mais se falaram também. Eu me lembro que ele falou assim, me mandou um e-mail: "Roubaram meu passaporte! Socorro!". Ai nunca mais [o vi]! Faz uns três anos isso [...] Ele tava na Suiça! Roubaram o passaporte dele e: "Socorro!".E nunca mais. Mando e-mail pra ele, não responde, nunca mais respondeu. Sumiu, simplesmente desapareceu. Então isso ai pra mim não serve, sabe? Sair, se aventurar assim. (Frank, Porto Alegre)

Em relação às narrativas apresentadas por Frank e Thor, por se tratar de relatos de "segunda mão", ou seja, contados por pessoas que não vivenciaram de fato as experiências de exploração, mas apenas reportaram histórias de conhecidos, fica difícil inferir mais detalhes sobre cada um desses casos. Porém, a partir dos elementos trazidos nessas narrativas, essas situações poderiam facilmente ser tipificadas por instituições jurídicas internacionais como "tráfico de pessoas", se considerarmos as definições presentes no Protocolo de Palermo. O Protocolo de Palermo é um instrumento legal internacional que trata sobre o "tráfico de pessoas". Tal documento foi elaborado em 2000 pela Organização das Nações Unidas (ONU), e ratificado pelo Brasil em 2004, por meio do decreto $\mathrm{N}^{\circ} 5.017$, de 12 de março de 2004. O discurso de proteção contido no Protocolo de Palermo recai especialmente sobre mulheres e crianças, uma vez que, historicamente, esse foi o grupo considerado mais vulnerável em relação ao tráfico de pessoas (Doezema, 1998; Kempadoo, 1998; Piscitelli e Vasconcelos, 2008). No entanto, acho importante destacar que essas situações que envolvem a exploração de pessoas em contextos migratórios aparentemente também habitam o imaginário de homens que viajam (ou planejam viajar) para o exterior a fim de trabalhar no mercado do sexo.

No caso relatado por Frank, não sabemos se o roubo do passaporte do seu colega foi decorrente da tentativa de algum tipo 
de exploração (sexual, laboral, serviços forçados, etc.). Já no caso do garoto com quem Thor teve contato, o sujeito aparentemente estava envolvido com algum tipo de "problema". Porém, não podemos afirmar, com convicção, que se tratava de algo relacionado a algum tipo de "rede de tráfico de pessoas". Que problema seria esse? Dívidas por drogas? Disputas territoriais? Rixas pessoais com terceiros? O relato de Thor é impreciso quanto a essas especificações, o que nos coloca diante da impossibilidade de afirmar que se tratava de um caso de envolvimento com alguma "rede de exploração/tráfico de pessoas". Thor também afirmou ter conhecimento de histórias de outros garotos que se envolveram em situações de apreensão de documentos, de facilitação de transferência e alojamento de pessoas para/no exterior a partir de propostas enganosas que resultavam em acúmulos de dívidas, etc. Alguns dos elementos presentes nessas histórias poderiam ser interpretados, em muitos países, como "tráfico de pessoas", independentemente do tipo de exploração a qual os sujeitos foram submetidos. Como bem salientam Piscitelli e Vasconcelos (2008:13), no Protocolo de Palermo

[...] tráfico de pessoas não é sinônimo de prostituição, nem é reduzido à 'exploração da prostituição'. Ele abrange o trabalho forçado, escravatura ou práticas similares a ela ou servidão que podem ser situações observadas em qualquer atividade. Além disso, inclui, ainda, os deslocamentos realizados nas condições acima assinaladas para a remoção de órgãos [...] [grifo das autoras].

Várias definições conceituais encontradas no Protocolo de Palermo, como prostituição (forçada ou consensual), exploração, tráfico, etc., são alvos de críticas e de constantes reformulações e ressignificações. Esse tenso debate é atravessado por diversas interpretações jurídicas que se articulam às leis nacionais de cada país e por debates travados entre distintas visões políticas, em especial entre as diversas correntes feministas (Kempadoo, 2005, 2016; Chapkis, 2005; Piscitelli, 2006; Piscitelli e Vasconcelos, 2008). 
Considerando as histórias dos garotos que nunca foram para o exterior, bem como daqueles que já tiveram alguma experiência como trabalhador do sexo fora do Brasil, pude ir estabelecendo algumas reflexões acerca dos imaginários desses fluxos transnacionais. No geral, não conheci nenhum garoto que tivesse, ele mesmo, vivenciado alguma situação que poderia ser considerada "tráfico de pessoas" e/ou "exploração sexual para fins comerciais". Tampouco escutei relatos que expressassem experiências pessoais que fossem significadas nesses termos. É curioso observar que as histórias que apresentavam temas que poderiam ser relacionados à questão do "tráfico de pessoas" sempre me foram relatadas na terceira pessoa. Tais narrativas sobre um "outro vitimado" apareceram de forma imprecisa e sem muitas convicções, por parte dos informantes, se de fato o sujeito em questão estava em uma situação de "tráfico" e/ou "exploração". Por que, então, alguns interlocutores pareciam associar situações que envolvessem algum tipo de "risco" ou "perigo" à ideia de "tráfico de pessoas"? Não pretendo arriscar nenhum tipo de interpretação fácil que seja capaz de dar conta de explicar essas construções imaginárias. No entanto, não posso deixar de pontuar que me parece que muitas dessas histórias reproduzem um certo roteiro daquilo que está enunciado nas "políticas antitráfico", amplamente disseminadas em países Europeus a partir de dispositivos salvacionistas que constituem aquilo que Laura Agustín (2007) denominou de "indústria do resgate".

Segundo Blanchette e Silva (2011), os movimentos antitráfico que compõem o complexo da indústria do resgate repetem estatísticas inventadas e disseminam pesquisas apocalípticas sem fundamentos epistemológicos, criando, assim, no imaginário público, a imagem da "típica experiência da pessoa traficada" - quase sempre imaginada como sendo uma mulher (Blanchette e Silva, 2011:80). Concordando com autoras/es como Agustín (2007), Blanchette e Silva (2011), Mitchell (2019), Kempadoo (2005; 2016) e Piscitelli (2012), considero que tais políticas têm produzido, nos últimos anos, um modelo de captura 
de corpos, subjetividades e imaginários que faz circular uma política do medo que funciona como uma tecnologia eficaz no controle das fronteiras transnacionais, especialmente em relação aos/às migrantes de países do sul global e/ou países subalternos. A partir dos relatos dos meus interlocutores, pude observar que tais agenciamentos de enunciação, que prescrevem e produzem imaginários acerca dos fluxos de pessoas, subjetivam também os homens trabalhadores do sexo que cogitam viajar e/ou que viajam para o exterior. Além do mais, todo esse campo de forças pode balizar os modos pelos quais esses sujeitos se posicionam diante das (im)possíveis experiências de mobilidade.

Um exemplo sobre perspectivas aparentemente conflitantes no que diz respeito à interpretação analítica do fenômeno da indústria do sexo e suas relações com os fluxos de pessoas através das fronteiras, pode ser visto em uma comparação entre discursos de uma matéria jornalística publicada pelo jornal El País e a análise da pesquisa desenvolvida pela Fundación Triángulo, citada anteriormente ${ }^{14}$. Em 2010, o jornal espanhol El País publicou uma reportagem sobre o que foi considerada a "primeira desarticulação de uma rede de exploração de prostituição masculina na Espanha ${ }^{15}{ }^{16}$. Segundo a matéria, a maioria dos homens que estavam sendo explorados por essa rede era de brasileiros. De acordo com o jornal, 80 homens brasileiros teriam sido atraídos para a Espanha para trabalhar como bailarinos ou modelos. A narrativa midiática ainda destaca que alguns sabiam que iriam atuar como garotos de programa, outros não; e que para manter esses homens sexualmente ativos, era-lhes oferecido

\footnotetext{
${ }^{14}$ Para um profícuo debate sobre a confusão entre a "produção de dados e fatos" sobre a questão do "tráfico de pessoas" (dados geralmente oriundos de reportagens jornalísticas e de processos jurídico-legais descontextualizados) e a construção de categorias analíticas que visem à análise desses fenômenos, conferir o artigo produzido pelo Grupo Davida (2005).

${ }^{15}$ Fonte: http://elpais.com/diario/2010/09/01/sociedad/1283292002 850215.html

${ }^{16}$ Uma análise pormenorizada sobre a cobertura midiática a respeito da desarticulação dessa suposta rede de exploração de prostituição masculina na Espanha pode ser conferida no artigo de Gregory Mitchell (2019).
} 
Viagra para que pudessem ter um bom rendimento sexual com os clientes.

Os dados apresentados na matéria do El País coincidem, em partes, com as informações da pesquisa da Fundación Triángulo, que apontou que a maior parte dos homens trabalhadores do sexo na Espanha era composta por brasileiros. Nessa pesquisa (anterior à publicação da matéria jornalística), no entanto, não se constatou a presença de redes de exploração sexual, nos moldes denunciados pelo jornal citado. Segundo a publicação da Fundación Triángulo (2006:33), no âmbito da prostituição masculina a figura do rufián (rufião) - sujeito que trafica seres humanos para fins de exploração sexual - "não se encontra institucionalizada, nem parece existir". Por outro lado, a figura dos proxenetas - aqueles que recebem uma porcentagem do que é arrecadado com o serviço sexual - é encontrada nos pisos, locais onde os garotos exercem o trabalho sexual. A análise da Fundación Triángulo, desenvolvida a partir da uma pesquisa que escutou os trabalhadores do sexo, nos fornece uma interpretação que nos parece ser um pouco mais próxima das percepções dos próprios garotos imigrantes:

No hemos tenido constancia hasta la fecha de hombres que hayan sido víctima de redes de tráfico de personas para fines de explotación sexual, sin embargo hemos conocido casos de trabajadores sexuales de origen latinoamericano, en concreto brasileño, que se financian entre sí el viaje de llegada a España contrayendo una deuda a la que suman unos intereses determinados. Es sabido por parte de los hombres que deciden emigrar a España que sus conocidos o amigos ejercen prostitución. El contemplar los recursos económicos que les reporta les anima a introducirse en el mundo del trabajo sexual. Estas relaciones son entendidas por el grupo como de ayuda y solidaridad, no como redes de tráfico de personas ya que, en primer lugar los recién llegados no están obligados a ejercer prostitución para saldar la deuda contraída y en segundo lugar en el caso de que ejerzan prostitución, lo hacen bajo sus propias condiciones (Fundación Triángulo, 2006:33) [grifos nossos]. 
Ressaltamos a importância de se considerar essa análise, pois ela foi construída a partir da escuta direta de homens trabalhadores do sexo imigrantes que estavam atuando na Espanha. Além disso, a pesquisa da Fundácion Triángulo apresenta um cuidado maior para definir as posicionalidades dos sujeitos nas redes do mercado do sexo e as peculiaridades locais das micropolíticas territoriais. Nesse sentido, trata-se, aparentemente, de uma visão mais próxima das experiências vividas pelos sujeitos envolvidos com a prostituição. Contrariamente, o tom narrativo da matéria publicada pelo jornal El País trata a todos os trabalhadores do sexo como "vítimas que buscavam um futuro na Espanha" sem mesmo ouvir o que esses sujeitos tinham a dizer sobre as próprias experiências. Essa é uma retórica frequente, que se direciona a proteção de "pessoas vulneráveis" e ao resgate de "vítimas". No entanto, como bem apontou Laura Agústin (2007) a partir de suas pesquisas junto aos/as trabalhadores/as do sexo em contextos transnacionais, aquelas pessoas que são consideradas como "necessitadas de ajuda" muitas vezes não se definem nesses termos "vitimizantes" ("vítimas", "vulneráveis", "traficadas", etc.). As opiniões sobre suas próprias experiências, no entanto, raramente são levadas em consideração, como apontam Agustín (2007) e Kempadoo (2016). De maneira semelhante, Adriana Piscitelli (2012) também destaca, a partir de suas pesquisas etnográficas realizadas com trabalhadoras sexuais brasileiras que atuavam na Espanha, que as significações que essas mulheres davam às suas experiências divergiam daquelas noções de prostituição e tráfico de pessoas contidas em documentos legais e protocolos internacionais. Não queremos defender aqui que a exploração sexual de homens imigrantes não possa ocorrer em contextos de migração, mas ressaltamos a necessidade de analisarmos essas experiências a partir de difusos fenômenos sócio-antropológicos que lhes são inerentes. Concordamos, nesse sentido, com Sandro Mezzadra (2005), que destaca a importância de uma perspectiva multidisciplinar para atentarmos à densidade histórica, subjetiva $e$ antropológica dos sistemas migratórios. 
Pesquisadoras que vêm investigando a atuação de mulheres nos mercados transnacionais do sexo, como Doezema (1998), Kempadoo (1998, 2005, 2016), Chapkis (2005), Piscitelli (2006, 2013) e Agustín (2007), apontam que os discursos que tendem a posicionar as trabalhadoras do sexo como "vítimas vulneráveis, passivas e sem agência" muitas vezes são construídos sob perspectivas imperialistas, colonialistas e racializadas. As mulheres do "terceiro mundo" e de países pobres seriam percebidas como "vítimas que precisariam de ajuda", ao passo que as de países desenvolvidos seriam vistas como "emancipadas $e$ independentes". Piscitelli (2006:22), na esteira dessas críticas, destaca que os discursos sobre "tráfico" teriam sido embasados por "visões 'ocidentais' de pessoas que não trabalham na indústria do sexo". Tais discursos seriam, assim, responsáveis por constituir a ideia de que "qualquer mulher do Terceiro Mundo que atravesse as fronteiras para oferecer serviços sexuais tenda a ser percebida como vítima de abuso de poder ou de uma posição de vulnerabilidade" (Piscitelli, 2006:22). Ao comparar a retórica jornalística do jornal El País com a análise interpretativa da pesquisa da Fundación Triángulo, suspeitamos que essa mesma lógica discursiva (resguardando as diferenças de gênero que não podem ser menosprezadas) recaia sobre os homens trabalhadores do sexo em situações migratórias. Em uma perspectiva analítica semelhante, Gregory Mitchell (2019), ao analisar a cobertura midiática sobre o caso da suposta rede de tráfico de homens na Espanha, também considera que há uma tentativa sensacionalista que faz parecer que o tráfico de pessoas para fins sexuais está piorando e que "nem mesmo os homens estariam mais a salvos".

Sem termos a pretensão de nos aprofundarmos nesse debate e/ou destrinchar uma reflexão mais complexa que se relacione à polêmica questão do tráfico de pessoas, chamamos a atenção para o fato de que essa temática também parece atravessar o imaginário de homens trabalhadores do sexo. Há uma certa percepção de que sair do país para trabalhar como boy envolvem riscos que alguns escolhem enfrentar e outros preferem evitar. Os riscos de cair em redes de exploração no exterior 
acabam operando como uma forma subjetiva de "gestão invisível do medo". Se por um lado vemos instrumentos jurídicos, como o Protocolo de Palermo, que pretendem proteger "vítimas do tráfico de pessoas", por outro lado não vemos movimentos com igual força legal em defesa do trabalho como um direito fundamental, da livre circulação de pessoas por entre fronteiras nacionais, e de uma postura radical anti-xenofobia e anti-racismo. Muito pelo contrário. $\mathrm{O}$ que temos observado em contextos globais (especialmente entre países do norte global) é o recrudescimento de políticas migratórias mais austeras, de sentimentos xenofóbicos $e$ de discursos nacionalistas que tendem a tratar o "outro" estrangeiro como bode-expiatório culpado pelos problemas sóciopolíticos de um país. Autoras como Agustín (2007) e Kempadoo (2016) problematizam o discurso do "resgate" que se direciona a pessoas supostamente traficadas, bastante recorrente em muitos países europeus. Segundo Agustín, haveria um paradoxo e uma incoerência entre as posições salvacionistas que pretendem resgatar $e$ proteger pessoas em situação de migração $e$ os discursos anti-migração que proliferam na Europa:

$\mathrm{Na}$ Europa, uma contradição fundamental representa os incoerentes programas dedicados aos/às migrantes, uma vez que a retórica padrão sobre inclusão social e direitos civis se direciona a políticas excludentes de imigração nacional. Haja vista que muitos migrantes não têm permissão para trabalhar legalmente ou usufruir os direitos de cidadãos fora de seus países de origem, a única voz de ajuda que eles/elas gostariam de escutar seria papéis: não importa o quão burocráticos sejam os documentos requeridos ${ }^{17}$ (Agustín, 2007:193).

Consideramos que as políticas migratórias excludentes; os discursos sobre tráfico de pessoas - frequentemente apoiado em perspectivas abolicionistas, neoliberais $e$ sensacionalistamidiáticas, como aponta Kempadoo (2016); e a falta de

${ }^{17}$ Tradução livre do original em inglês. 
dispositivos que realmente protejam os direitos e que reconheçam a humanidade de migrantes que atuam nos mercados do sexo (ao invés de deportá-los para seus países de origem sob a retórica da "proteção"), sejam elementos que, combinados, produzem a sensação do risco e o afeto do medo de sair do país. Esses elementos instalam uma gestão invisível do medo e constituem uma forma governamental efetiva para se controlar os fluxos migratórios de pessoas. Trata-se de uma racionalidade biopolítica para o controle das fronteiras nacionais e para a tentativa de manutenção de uma coesão da vida social que exclui os diferentes e os estrangeiros, sobretudo aqueles/as que ousam habitar as margens das moralidades e normas sexuais hegemônicas. Medo como afeto biopolítico, como diria Vladimir Safatle (2016), que percorre as sociedades Modernas como uma forma efetiva de controle dos indivíduos e de gestão das populações:

\section{[...] Compreender sociedades como circuitos de afetos implicaria partir dos modos de gestão social do medo, partir de sua produção e circulação enquanto estratégia fundamental de aquiescência à norma. Pois, se, de todas as paixões, a que sustenta mais eficazmente o respeito às leis é o medo, então deveríamos começar por nos perguntar como ele é produzido, como ele é continuamente mobilizado (Safatle, 2016:16)}

Apesar dessas tentativas de controle das fronteiras via gestão biopolítica das populações, o que temos observado é que essas formas de controle não são totalmente eficazes e as migrações, independentemente dos fatores que as motivam, acontecem com bastante frequência e sob diversas condições. Essa realidade não poderia, portanto, ser diferente no contexto do mercado transnacional do sexo e entre trabalhadores/as do sexo migrantes.

\section{Considerações finais}

Nesse artigo, buscamos ensaiar uma problematização acerca da inserção dos homens brasileiros no mercado transnacional do 
sexo. A questão da prostituição masculina no Brasil tem sido pouco debatida, ainda que recentemente tenhamos visto alguns estudos que têm se dedicado ao tema. Os fluxos migratórios de garotos de programa, seja dentro do próprio país ou para o exterior, no entanto, ainda é um fenômeno bastante invisibilizado nas produções acadêmicas brasileiras, nos movimentos sociais $e$ nas políticas públicas. Consideramos que um olhar atento a essas mobilidades podem fornecer preciosas contribuições, tanto para estudos de gênero e sexualidade como para os estudos sobre migrações. Salientamos a importância de articular esses dois campos de pesquisa para que possamos problematizar com mais acuidade e atenção a complexidade dos sistemas migratórios, as relações de poder que os atravessam e os modos de subjetivação que eles produzem.

O esboço de um mapa sócio-político apresentado no começo deste texto $e$ a análise de algumas narrativas $e$ imaginários que atravessam a micropolítica do cotidiano dos trabalhadores do sexo, compõem uma cartografia do mercado do sexo. As reflexões apresentadas não se encerram aqui, porém consideramos que tais problematizações podem visibilizar um tema pouco debatido, bem como refinar um olhar crítico nas pesquisas sobre trabalho sexual e migração.

\section{Referências bibliográficas}

Agustín, Laura. Sex at the margins. Migration, Labour, Markets and the Rescue Industry. London \& New York: ZedBooks, 2007.

BARRERO, Gloria Patricia Díaz. Stripers, bailarinas exóticas, eróticas: identidad e inmigración en la construcción del Estado Canadiense. cadernos pagu (25), 2005, pp.129-152.

CASTAÑEDA, Heide. Migrant male sex works in Germany. In: MINICHIELLO, Victor \& SCOTT, John (orgs.). Male Sex Work and Society. Harrington Park Press, 2014.

CHAPKIS, Wendy. Soft Glove, Punishing Fist: The trafficking Victims Protection Act of 2000. In: BERNSTEIN, Elizabeth; SCHAFFNER, Laurie 
(Ed.). Regulating Sex. The politics of intimacy and identity. New York and London: Routledge, 2005.

DoezemA, Jo. Beyond the Voluntary v. Forced Prostitution Dichotomy. In: KeMPADOO, Kamala; DoEZEMA, Jo. (Orgs.). Global Sex Workers. Rights, Resistance, and Redefinition. New York, Routledge, 1998.

DUGGAN, Lisa. What the pathetic case against RentBoy.com says about sex work. The Nation. New York, 7 Jan. 2016. Disponível em: https://www.thenation.com/article/what-the-pathetic-case-againstrentboy-com-says-about-sex-work/. Acesso em: 08 jul. 2017.

FERNÁNDEZ, Ana Maria. Las lógicas colectivas. Imaginarios, cuerpos y multiplicidades. Buenos Aires: Editorial Biblos, 2008.

FUNDACIÓN Triángulo. Trabajadores masculinos del sexo: aproximación a la prostitución masculina en Madrid. Madri: Fundación Triángulo, 2006.

GRUPO Davida. Prostitutas, "traficadas"e pânicos morais:uma análise da produção de fatos em pesquisassobre o "tráfico de seres humanos". cadernos pagu (25), 2005, pp.153-184.

KEMPADOO, Kamala. Rethinking Sex Work. In: Kempadoo, Kamala; Doezema, Jo. (Orgs.). Global Sex Workers. Rights, Resistance, and Redefinition. New York, Routledge, 1998.

KeMPADOO, Kamala. Mudando o debate sobre o tráfico de mulheres. cadernos pagu (25), Campinas-SP, 2005, pp.55-78

KEMPADOO, Kamala. Revitalizando o imperialismo: campanhas contemporâneas contra o tráfico sexual e escravidão moderna. Cadernospagu (47), 2016.

KeMPADOO, Kamala; DoEZEMA, Jo.(Orgs.). Global Sex Workers. Rights, Resistance, and Redefinition. New York, Routledge, 1998.

MAYORGA, Cláudia. Cruzando fronteiras: prostituição e imigração. cadernos pagu (37),Campinas-SP, 2011, pp. 323-355.

MCGRATH-LONE L et al. The sexual health of male sex workers in England: analysis of cross-sectional data from genitourinary clinics. Sex TransmInfect, online edition. DOI: 10.1136/sextrans2013-051320, 2013. 
MEZZADRA, Sandro. Derecho de fuga.Migraciones, ciudadanía y globalización. Traducción: Miguel Santucho. Madrid. Traficantes de Sueños, 2005.

MITCHELL, Gregory. Fare Tales and Fairy Tales: how gay sex tourism is shaping the Brazilian Dream. Wagadu. Volume 9, Spring 2010.

MitCHELl, Gregory. Padrinhos gringos: turismo sexual, parentesco queere as famílias do futuro. In: PISCITELLI, Adriana; ASSIS, Gláucia de Oliveira; OlIVAR, José Miguel Nieto (orgs.). Gênero, sexo, amor e dinheiro: mobilidades transnacionais envolvendo o Brasil. Campinas, SP: Unicamp/PAGU, 2011a.

MITCHELL, Gregory. Turbo Consumers ${ }^{\mathrm{TM}}$ in paradise: tourism, civil rights, and Brazil's gay sex industry. American Ethnologist. Vol.38, №4, 2011b, pp.666-682.

MitCHELl, Gregory. The garotos from Brazil: Xenophobia and the Sex Trafficking of Men. In: Routledge International Handbook of Sex Industry Research. Eds. Isabel Crowhurt, Susan Dewey, and China Izugbara. Routledge. Forthcoming, 2019.

NETWORK of Sex Work Projects. Good practice guidance - Working with Migrant Sex Workers. London: UKNSWP, 2008.

PELÚCIO, Larissa. "Amores perros" - sexo, paixão e dinheiro na relação entre espanhóis e travestis brasileiras no mercado transnacional do sexo. In: PISCITELli, Adriana; AsSIS, Gláucia de Oliveira; OlIVAR, José Miguel Nieto (orgs.). Gênero, sexo, amor e dinheiro: mobilidades transnacionais envolvendo o Brasil. Campinas, SP: Unicamp/Pagu, 2011.

PERLONGHER, Néstor. O negócio do michê. A prostituição viril em São Paulo. São Paulo: Editora Fundação Perseu Abramo, 2008.

PISCITELli, Adriana. Apresentação: gênero no mercado do sexo. Cadernos pagu (25), Campinas-SP, pp.7-23.

PISCITELLI, Adriana. Sujeição ou subversão: migrantes brasileiras na indústria do sexo na Espanha. História e Perspectivas, Uberlândia (35), 2006, pp. 13-55.

PISCITELli, Adriana. Revisiting notions of sex trafficking and victims. Vibrant, Virtual Braz. Anthr., Brasília, v. 9, n. 1, 2012, pp. 274-310. 
PISCITElli, Adriana. Trânsitos. Brasileiras nos mercados transnacionais do sexo. Rio de Janeiro: EdUERJ, 2013.

PISCITElli, Adriana; Assis, Gláucia de Oliveira; OlIVAR, José Miguel Nieto (orgs.). Gênero, sexo, amor e dinheiro: mobilidades transnacionais envolvendo o Brasil. Campinas, SP: Unicamp/PAGU, 2011.

PISCITElli, Adriana; VASCONCElOS, Marcia. Apresentação (Dossiê: Gênero no Tráfico de pessoas). Cadernos pagu, Campinas, n. 31, pp. 9-28, Dec. 2008.

Safatle, Vladimir. Circuito dos Afetos: Corpos políticos, Desamparo, Fim do Indivíduo. 2. Ed. Rev. -Belo Horizonte: Autêntica, 2016.

SANTOS, Daniel Kerry. Homens no mercado do sexo: fluxos, territórios e subjetivações. Tese de doutorado, Psicologia, UFSC, 2016.

Silva, Ana Paula; BlanchetTe, Thaddeus Gregory. Nossa Senhora da "Help": sexo, turismo e deslocamento transnacional em Copacabana. cadernos pagu (25), 2005, pp.249-280.

Silva, Ana Paula; BlanchetTe, Thaddeus Gregory. O mito de maria, uma traficada exemplar: confrontando leituras mitológicas do tráfico com as experiências de migrantes brasileiros, trabalhadores do sexo. Rev. Inter. Mob. Hum., Brasília, Ano XIX, No 37, pp.79-105, jul./dez. 2011 